\title{
A Giant Inguinoscrotal Hernia
}

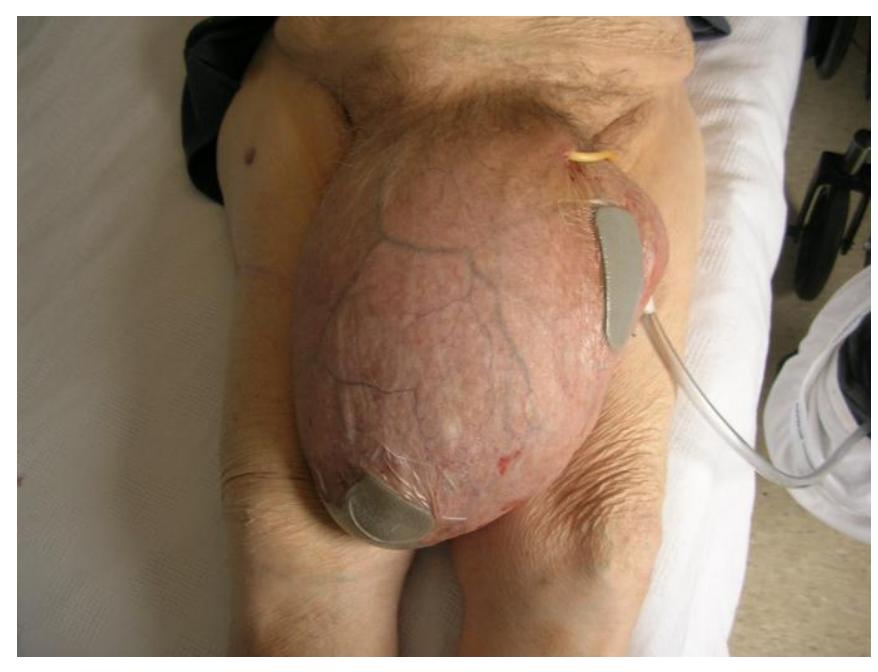

FIGURE. A giant inguinoscrotal hernia extending to the knee level.

Ivan Chernev

Department of Rehabilitation Medicine, Boston University Medical Center, Boston, MA

E-mail: ivantchernev@yahoo.com or Ivan.Chernev@bmc.org

Received November 5, 2009; Revised December 6, 2009; Accepted December 11, 2009; Published January 8, 2010

KEYWORDS: giant inguinoscrotal hernia

Giant inguinoscrotal hernias are uncommon nowadays, however, they may still occasionally present after years of neglect[1]. Significant morbidity and decreased quality of life may be associated with them. They may cause urinary retention, skin ulcers and infection, and decreased mobility apart from the classical complications of inguinoscrotal hernias[2].

A 71-year-old man with multiple medical problems, including chronic cardiac and pulmonary disease, was admitted to our inpatient rehabilitation unit after acute hospitalization due to pneumonia. During the routine physical examination, a huge inguinoscrotal hernia extending to the knee level was observed (see figure). The patient reported that he noticed the hernia 7 years ago and it has been increasing in size since then. His mobility was decreased due to the size of the hernia as well as general deconditioning. After discussion with the patient, the decision was made not to proceed with surgical treatment due to the significantly increased operative risk.

Although surgical treatment seems to be the only reasonable treatment for giant inguinoscrotal hernias, forced reduction of hernial contents back into the contracted peritoneal cavity may alter the intra- 
abdominal and intrathoracic pressures, leading to added morbidity and mortality. Several single- or multiple-stage surgical techniques have been described. These techniques include three different groups of surgeries. The first group consists of debulking the abdominal contents, i.e., omentectomy, bowel resection, and splenectomy[1,3]. The second group includes different procedures for enlarging the abdominal cavity, such as preoperative pneumoperitoneum, skin and muscle flaps, mesh patches, and phrenectomy[4,5]. The last group uses a combination of techniques from the first two groups. Regardless of the selected surgical management, the morbidity associated with giant inguinoscrotal hernias can be significant, with most of the cases reporting minor or major postoperative complications. Unfortunately, patients with giant inguinoscrotal hernias frequently have comorbid conditions, such as cardiac and pulmonary disease, which may complicate the surgery even further. In patients with multiple medical conditions, adequate preoperative preparation and postoperative monitoring is imperative in case surgical treatment is opted.

\section{REFERENCES}

1. Patsas, A., Tsiaousis, P., Papaziogas, B., Koutelidakis, I., Goula, C., and Atmatzidis, K. (2009) Repair of a giant inguinoscrotal hernia. Hernia. [Epub ahead of print]

2. Vano-Galvan, S., Guisado-Vasco, P., and Jaén, P. (2009) Giant inguinoscrotal hernia. Aust. Fam. Physician 38(4), 222-223.

3. $\quad$ El Saadi, A.S., Al Wadan, A.H., and Hamerna, S. (2005) Approach to a giant inguinoscrotal hernia. Hernia 9(3), 277279.

4. Kovachev, L.S., Paul, A.P., Chowdhary, P., Choudhary, P., and Filipov, E.T. (2009) Regarding extremely large inguinal hernias with a contribution of two cases. Hernia. [Epub ahead of print]

5. Valliattu, A.J. and Kingsnorth, A.N. (2008) Single-stage repair of giant inguinoscrotal hernias using the abdominal wall component separation technique. Hernia 12(3), 329-330.

This article should be cited as follows:

Chernev, I. (2010) A giant inguinoscrotal hernia. TheScientificWorldJOURNAL: TSW Clinical Images 10, 72-73. DOI 10.1100/tsw.2010.6. 


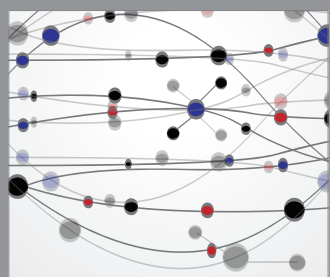

The Scientific World Journal
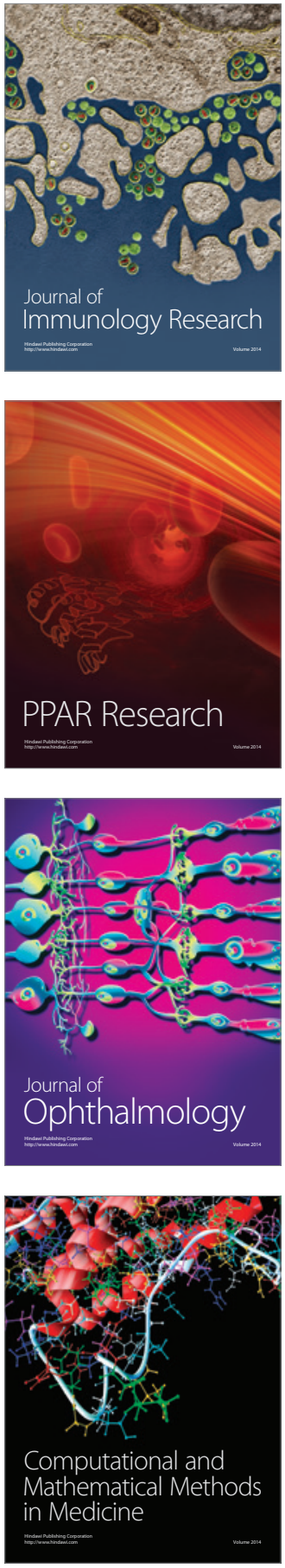

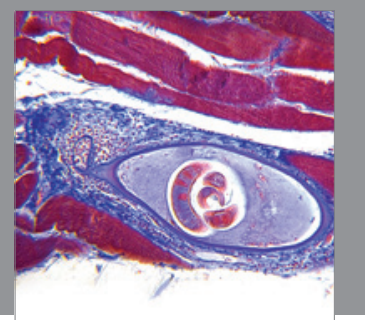

Gastroenterology

Research and Practice
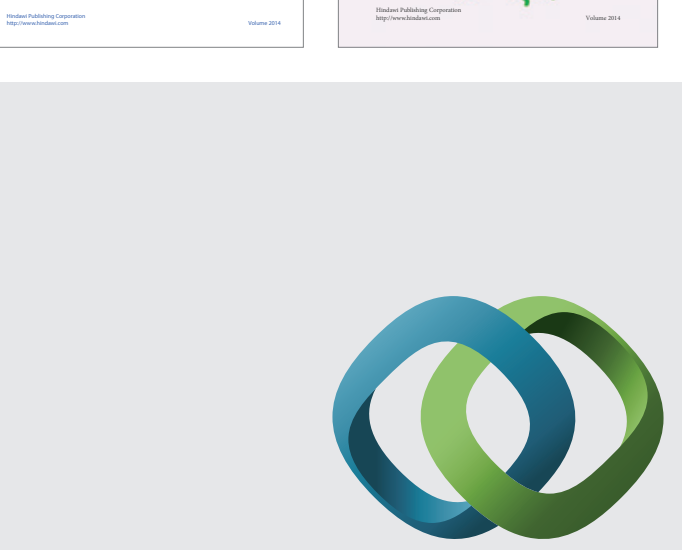

\section{Hindawi}

Submit your manuscripts at

http://www.hindawi.com
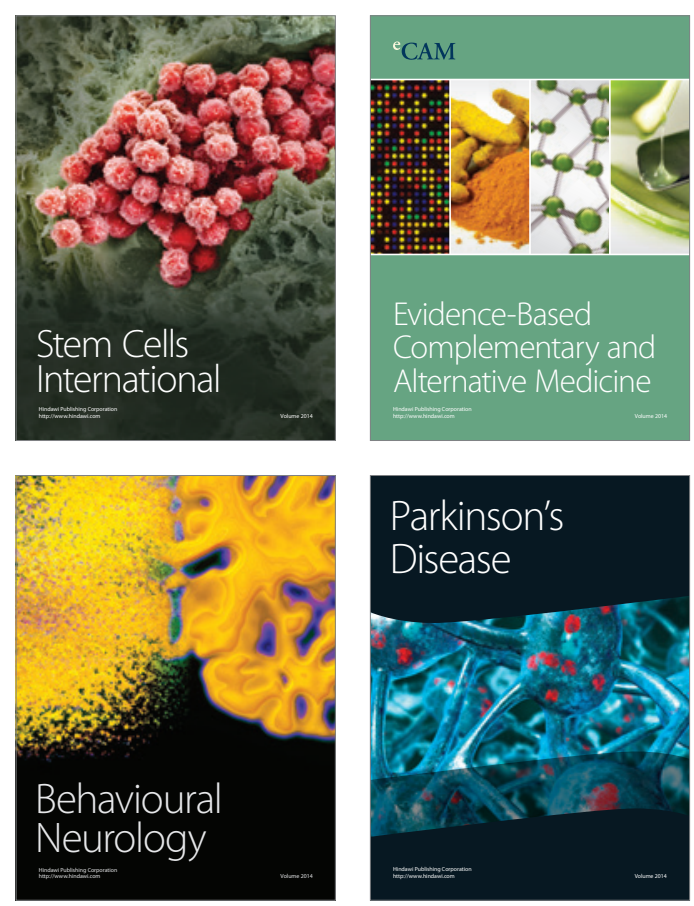

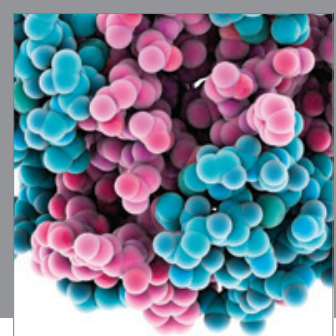

Journal of
Diabetes Research

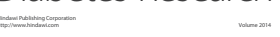

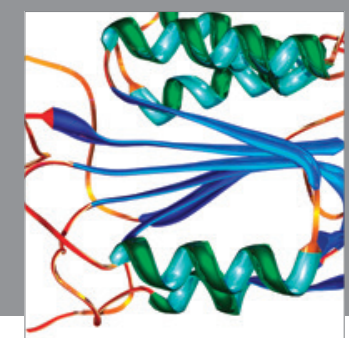

Disease Markers
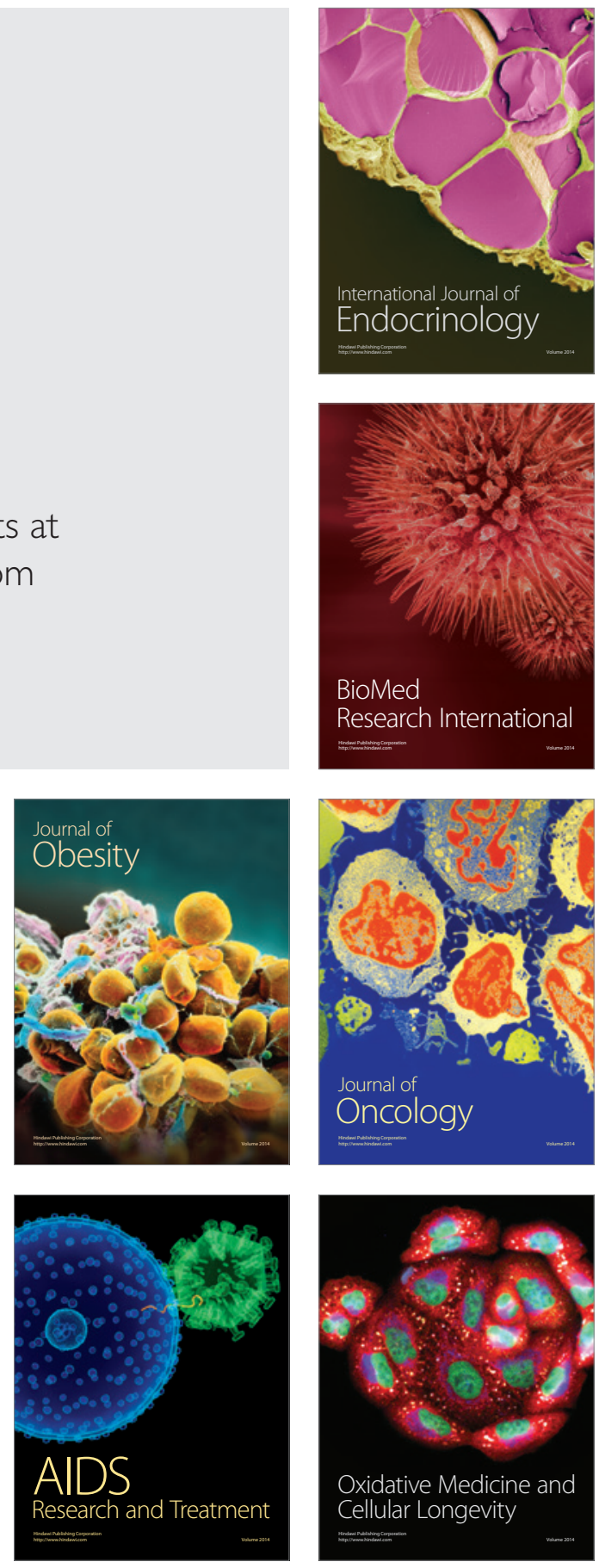